\title{
CONFIGURACIÓN DE LA MUERTE Y CULTURA REGIONAL EN ESPACIOS TRANSPUESTOS. UNA PROPUESTA TEÓRICO- METODOLÓGICA
}

\author{
Dr. Luis Ernesto Cruz Ocaña \\ Dr. Jorge Magaña Ochoa \\ UNIVERSIDAD AUTÓNOMA DE CHIAPAS
}

\section{Introducción}

El presente texto tiene como finalidad esbozar un conjunto de reflexiones teóricometodológicas que sirvieron de fundamento para una investigación doctoral en Estudios Regionales, cuyo objetivo fue analizar el proceso de configuración sociocultural y narrativa de la muerte en espacios concretos como Tuxtla Gutiérrez, Chiapas, México, donde se establece una lucha por las formas de significar el mundo y lo que en él sucede. Esta lucha constituye una cultura regional que, lejos de manifestar homogeneidades, revela las complejas mixturas elaboradas por quienes la habitan.

La muerte es algo de lo que, aunque no quisiéramos hablar ni escuchar, sabemos por experiencia que acompaña nuestra existencia humana. Pero esa experiencia no se refiere en ningún caso a una experiencia propia, sino a una experiencia indirecta, es decir, la experiencia de la muerte de otros, ajenos y próximos, que nos rodean.

De esa imposibilidad de experiencia directa surge también la dificultad de aproximarse a ella, en la medida que su irrupción es, por lo general, inesperada aunque sea medianamente aceptada- y sorpresiva -el momento de la culminación del proceso de morir es incierto-, de modo que genera en quienes permanecemos 
vivos emociones, acciones y reacciones diversas. Nos sobresalta en tanto seres corporales y afectivos, más que lógicos y racionales.

Si bien puede ser vista como un fenómeno físico-biológico en que nuestro organismo, por causas internas o externas y en momentos diferentes, cesa sus funciones vitales para dar principio a otro tipo de funciones -las funciones de muerte- (Quiroz Cuarón, 1986), es algo sobre lo que se realizan construcciones diversas. La significamos, vivimos y asignamos sentido, es decir, la configuramos de manera diferencial, no sólo alrededor del hecho mismo sino en torno a las formas en que se llevó a cabo y lo que sucede después de ella.

Este proceso simbólico en el que se producen, reproducen y apropian los significados no está libre de disputas y conflictos, se halla incluido en determinadas relaciones sociales de poder donde ciertas formas de significar el mundo y lo que en él sucede -como la muerte- buscan prevalecer sobre otras. Dicha prevalencia se relaciona más que con el contenido de los significados mismos, con un conjunto de condiciones y situaciones que históricamente se han conformado, así como con dispositivos de poder empleados con el fin de darles legitimidad. De ahí el interés por aproximarnos a la muerte a partir de cómo es concebida, experimentada y disputada en contextos específicos.

El estudio de la muerte requiere, en esta perspectiva, una mirada multidimensional y transdisciplinaria que no la reduzca dicotómicamente a una de sus partes: a) hecho natural o b) representación subjetiva; sino que intente aproximarse a ella y comprenderla como un símbolo producido y reproducido en una compleja red de relaciones de interdependencia donde participan grupos 


\section{ARTÍCULOS}

sociales e instancias como la Iglesia, el Estado, la prensa, las instancias médicas, el mercado, la academia, entre otras.

Para lograr lo anterior, el texto se organiza en cinco partes: la primera enfoca la muerte tanto como un hecho real como una construcción simbólica, al optar por un posicionamiento que, centrándose en lo socio-histórico y lo cultural, se dirige al conflictivo proceso de significación a partir del cual se concibe y experimenta la muerte.

La segunda aborda el poder como eje articulador del proyecto universalizador de sociedad y el proceso cultural cotidiano, así como categoría que permite trascender el debate entre lo micro y lo macro.

La siguiente parte relativiza la dicotomía estructura-actor al revisar nociones como imaginarios y prácticas que constituyen las operaciones de los sujetos en contextos pseudo-estructurados, agregando una discusión sobre la cultura regional como forma de aprehender los procesos de disputa locales y concretos.

La cuarta articula un modo de enfocar la muerte como idea, proceso y relación a través de la apuesta metodológica por el uso de los así denominados "relatos de muerte": relatos que tematizan la muerte del otro y la forma de vivir su ausencia.

En último lugar, se ofrecen algunas consideraciones finales a modo de recapitulación sumaria de los aportes de esta propuesta teórico-metodológica de investigación que apunta al tratamiento de un fenómeno que produce angustia, requiere de la dotación de sentido, pero también es producto de dispositivos de poder que insinúan ciertas formas de concebirla, experimentarla y actuar frente a ella, con la consiguiente exclusión de formas alternativas. 


\section{La muerte como problema de investigación y reto epistemológico}

La muerte es un fenómeno complejo del que podemos decir mucho sin agotarlo por completo. Según diversos autores existen principalmente cuatro visiones de la muerte "arraigadas al interior de la sociedad [y] que [de múltiples maneras] han permeado la idea más común acerca de la muerte" (González González, 2000, p. 478). Estas visiones son: la filosófica, la religiosa y la científica. Esta última subdividida en dos: médico-clínica y demográfico-estadística.

Sin embargo, dichas visiones no son las únicas y tampoco existe entre ellas una separación tajante. Más allá de la reflexión especulativa que se debate entre su formulación como paso del ser al no-ser -la nada- o como tránsito trascendente, y la reflexión materialista que hace de la muerte un hecho biológico y poblacional de suspensión de las funciones corporales y de la participación efectiva en la vida y los intercambios socio-económicos, es posible observar otra vertiente para acercarse al fenómeno. Dicha vertiente la visualiza como algo a la vez físico y simbólico, con lo que se convierte "el facto biológico en factus socio-cultural" (Mendoza Luján, 2012, p. 9).

Desde una visión socio-cultural, la muerte no es solamente o es más que un fenómeno biológico que hace de ella algo banal sin ningún sentido de trascendencia -entendida ésta no en términos propiamente religiosos-, más que un problema demográfico que hace del muerto algo reemplazable en la medida que sólo se refiere a un dato numérico en una gráfica estadística, y más que un suceso médico que hace de las consecuencias del morir y del morirse en algo limitado a la 
experiencia personal inmediata en donde el único afectado es quien muere (Jankélévitch, 2004).

La muerte es algo que nos acontece en tanto seres de los que se pueden enunciar "predicados físicos" y "predicados psíquicos" (Ricoeur, 1996, p. 9) en una urdimbre difícilmente desentrañable. La muerte es el límite que implica un impedimento e imposibilidad de seguir viviendo pero, al mismo tiempo, un borde que nos permite percibirnos y sentirnos como seres vivientes. El sinsentido que, al parecer y aunque resulte paradójico, dota de sentido a la vida humana (Jankélévitch, 2004).

El ser humano no sólo muere, sabe que va a morir, pero el reconocimiento de su propia muerte no es dado como certeza inmediata dada a su propia capacidad lógico-racional. La relación con nuestra muerte está mediada indistintamente por la relación con la muerte de otros, la forma en que la muerte nos afecta se vincula con las repercusiones de sobrevivir a otras muertes, y su impacto sobre la duración de nuestro tiempo es asimilado a partir de la influencia en la duración del tiempo de otros que habitan con nosotros. Las muertes de los otros son, en términos de Levinas, nuestras "primera[s] muerte[s]" (1994, p. 110). Con cada una parece irse y quedarse algo de nosotros y de los otros.

Es sólo después de dichas muertes que podemos expresar: "como todo el mundo, antes de mí y después de mí, debo morir" (Ricoeur, 2003, p. 474). Pero es, como continúa el filósofo francés, "el único acontecimiento del que jamás podremos hacer la experiencia individualmente [...]. Porque no se trata de experiencia sino de imaginación, siempre a destiempo, siempre inminente. Demasiado pronto, demasiado tarde" (Ricoeur, 2008, p. 52). He ahí su carácter 


\section{ARTÍCULOS}

indecible como experiencia propia y concreta, únicamente narrable a partir del entramado imaginativo entre realidad y ficción donde el protagonista es el otro, el ausente y a cuya ausencia se busca dotar de sentido a partir de la vida de quien narra y quien es narrado.

La muerte trasciende, influye en las relaciones sociales cotidianas y sólo ahí cobra su significado. Es vivida y narrada con y para otros, de modo que remite necesariamente a la relación intersubjetiva mediada por el lenguaje y, por ende, la significación. El tiempo propio -mismo que parece ser detenido abruptamente por la experiencia de la muerte- es vivido y narrado también con y para otros (Ovalle, 2013). Por eso la relación humana no termina entre quien se ha ido y quienes permanecen vivos, pues prevalece una forma de intercambio simbólico (Baudrillard, 1980). El tiempo y la muerte son más que criterios existenciales ligados a una condición individual, forman parte de esa existencia que implica a los otros, cercanos y lejanos.

La muerte no se consuma con declarar la extinción de los procesos fisiológicos, sino que se legitima socialmente cuando se reconoce la imposibilidad de expresión y respuesta directa hacia los otros, hecho que implica, acto seguido, la exclusión del cadáver del mundo de los vivos a través de ciertas prácticas funerarias, por ejemplo el entierro o la cremación como las más comunes en nuestro contexto.

No obstante, también conlleva el intento de hacer permanecer al muerto, al difunto $^{1}$, en la memoria, sea mediante la construcción de sepulcros, mausoleos,

${ }^{1}$ El difunto, a diferencia del cadáver pensado como cuerpo inanimado o cosa retirada de las relaciones y la cotidianeidad humanas, "no es un individuo excluido de las funciones sociales". Es 
capillas, altares, u otro tipo de tratamientos rituales ligados a la religiosidad o a la tradición popular. Así, la muerte aparece como:

suceso biológico, un rito de paso, algo inevitable, un suceso natural, un castigo, extinción, el cumplimiento de la ley de Dios, absurda, separación, reunión, un tiempo de juicio [...] causa razonable para la cólera, depresión, negación, represión, frustración, culpa, alivio, absolución, incremento [...] y disminución de la religiosidad (Kalish en Jiménez, 2012, p. 5).

Este carácter paradójico muestra la infertilidad de acercarse a la muerte desde miradas reduccionistas y reificantes, puesto que todas las dimensiones se mezclan y conviven entre sí. La muerte no es una realidad dada en y por sí misma. Es un hecho sobre el cual se ensamblan significados siempre en disputa. Es así que lo que llamamos realidad, o en este caso muerte, no es una entidad autodeterminada, sino que participa de nuestras configuraciones, aunque también las condiciona.

De aquí se deriva el carácter performativo más que puramente ostensivo de los conceptos. En palabras de Jacorzynski, "un performativo expresa algo en vez de [sólo] comunicar, cambia algo en el mundo en vez de [sólo] constatarlo o describirlo" (2008, p. 336). Los conceptos no son tales si no conllevan la acción concreta que hace posible que nombren aquello que pretenden nombrar y, a la vez, definir, delimitar, normalizar. Los conceptos no son simples mediadores entre quien nombra y lo que se nombra, ni una mera herramienta para describir lo

alguien, no algo, que continúa presente, de una u otra forma, en el mundo de los vivos. Esto porque "la muerte no es un hecho, sino un estado" (Van der Leeuw en Thomas, 1983, p. 493). 
nombrado, sino que forman parte constitutiva de lo nombrado, tienen una incidencia directa en su formación y configuración (Moebius, 2012).

Los conceptos y los nombres asociados a ellos son más que signos o categorías teóricas, son y cumplen su función en tanto que símbolos, enclavados en un contexto socio-histórico específico. No dicen las cosas en sí, ni dicen lo que las cosas son, configuran lo que nombran en una relación compleja entre los seres humanos y las cosas; misma que es tanto de naturaleza cognoscitiva, como afectiva, instrumental y, por ello, conflictiva.

De ahí que uno de los problemas de la formación escrituraria y de la "gente caligráfica y tipográfica" sea el hecho de favorecer "abstracciones que separan el saber del lugar donde los seres humanos luchan unos con otros" (Ong, 1987, p. 40, 49), es decir, sus entornos de producción y reproducción cotidianos.

Siendo de este modo, el referente "muerte" aparece como un concepto, un nombre, un significante sobre el cual se construyen significados a veces complementarios, a veces contrapuestos. Es aquí donde las dimensiones histórica, social y cultural de la vida humana cobran importancia en su definición; en tanto que aquéllas nos remiten no al significante o al significado por sí mismos, sino al complejo y conflictivo proceso cotidiano de significación en donde se autorizan y legitiman, en circunstancias históricas particulares, ciertos discursos que implican una serie de significados que, a su vez, excluyen otros. En tanto construcción lingüístico-simbólica que se nombra y se significa diferencialmente, implica también formas distintas de vivirla, de experimentarla.

Este enfoque con respecto a la muerte remite a un planteamiento interpretativo que, de acuerdo con los planteamientos del filósofo francés Paul 


\section{ARTÍCULOS}

Ricoeur (2002), pone a la explicación como el momento metodológico y a la comprensión como el momento no metodológico que envuelve al anterior. Implica establecer un vínculo entre el análisis de las estructuras y la hermenéutica o, en otros términos, de los dispositivos de poder y los mecanismos de producción de sentido.

De esta manera, la aproximación hermenéutica empleada busca incluir como elemento fundamental las relaciones de poder inherentes a cualquier relación humano-social para orientarse, más que a la dimensión semántica de los significados, hacia el proceso de construcción de ellos de acuerdo con posiciones diferenciadas entre grupos y agentes en el espacio social. Es así que toda configuración del mundo y lo que en él sucede se lleva a cabo en un contexto pseudo-estructurado que busca establecer los marcos de lo posible, aunque siempre deja espacios para la innovación y la transformación. Existen reglas y normas, pero, también, la posibilidad de transgredir y jugar con esas reglas y normas.

\section{La muerte en la sociedad y la cultura: el poder como articulación de la dicotomía macro-micro}

La muerte es, para Aguilera y González (2009), de acuerdo con una postura filosófica moderna, el "desorden" inmanente a la condición humana que impulsa la formulación de un orden que exceda su propia condición finita. Es por eso que la muerte parece encontrarse en la raíz de los grandes proyectos humanos, uno de los cuales es la invención de la sociedad, entendida como plan o modelo de ordenamiento ajustado a reglas y normas establecidas de acuerdo con un criterio 


\section{ARTÍCULOS}

de racionalidad devenido del pensamiento ilustrado occidental (De Marinis, 2005). Dicha racionalidad basada en principios de una lógica específica, con altas dosis de sistematicidad, coherencia, y búsqueda de homogeneidad en aras de una proyección de carácter universal, fue el basamento del proyecto de sociedad racional que, de múltiples formas, excluyó otras formas de ser y habitar el mundo.

Tal proyecto societal, que se distingue de lo social entendido como el carácter propiamente relacional e interdependiente de los seres humanos, buscó articular las diferencias surgidas de su propio proceso de establecimiento de una identidad bien definida que construye otredades como exterioridades constitutivas, para la conformación de unidades aparentemente integradas y compactas (Moebius, 2012).

Esa articulación requirió, a su vez, el surgimiento de dispositivos de poder institucionalizados que, de acuerdo con criterios de demarcación de la normatividad y la normalidad, se dirigieron hacia la vigilancia y el disciplinamiento constante de los sujetos humanos. Su objetivo era y sigue siendo orientar, regular y administrar lo que se hace en y con la vida e, incluso, lo que se hace en y con la muerte, a través del establecimiento de una manera específica de concebir tanto la vida como la muerte.

Pero ese orden societal -con el Estado como su garante primordial, la idea de nación como su contraparte cultural e identitaria, y la dotación de un territorio como su espacio de acción- es, como todo proyecto, un orden disputado, no definitivo sino contingente (Escalona, 2011) en razón de una doble falla: la falla inherente al modelo en sí por la carencia de un original y la falla en la propia forma de representar ese modelo por parte de los sujetos sociales en su cotidianeidad. 
A pesar de sus incesantes intentos por producir y reproducir un conjunto de significados compartidos en los individuos que lo conforman no es capaz de tener un control total sobre el proceso de significación cotidiano. Éste es mucho más dinámico de lo que el proyecto de sociedad racional reconoce. Incluye el azar, la innovación y la creatividad espontánea, constante, impredecible y subversiva (De Certeau, 1997).

Tal proceso de significación, que no es otro que el "proceso cultural" de producción-creación, distribución-reproducción y consumo-apropiación de los significados sociales, es el que da dinamismo y especificidad al proyecto de sociedad instaurado en escenarios concretos. La cultura, sea colocada con "C" mayúscula o nombrada en términos de unicidad de rasgos o características, sólo aparece como coherente, sistemática y consensuada -en otras palabras, canónicaen su dimensión hegemónica, donde se le cosifica y se le hace pasar como algo que trasciende la acción humana, obliterando su efervescencia cotidiana (Wright, 2004).

En síntesis, mientras la sociedad es el proyecto de ordenamiento con tendencias universalizantes y globalizantes, el proceso cultural es la manera como ese orden es disputado por los sujetos y sus grupos en lo local y lo cotidiano. El proceso cultural particulariza la recepción, uso y forma de vivir el proyecto societal y sus dispositivos institucionalizados en contextos específicos, pues su amplia influencia es hoy un hecho innegable².

\footnotetext{
2 De acuerdo con Asad: el 'Occidente' no es un mero mito hegeliano, ni una mera representación [...] Para bien o para mal, informa de modos sistemáticos innumerables intenciones, prácticas y discursos. Esto no es decir que existe una cultura Occidental integrada, o una identidad occidental fija, o una sola manera de pensar, sino que una singular identidad colectiva se auto-define en términos de una historicidad única en contraste con todas las demás, una historicidad que cambia de un lugar a otro [...] hasta abarcar el mundo (traducción nuestra) (1993, p. 18-19).
} 
Es en este punto donde el poder actúa como elemento articulador, puesto que, por un lado, el proyecto societal busca imponerse a partir de la contundencia de sus argumentos racionales, y, por el otro, el proceso cultural vivido en su interior manifiesta las relaciones de poder concretas entre quienes conforman dicho proyecto.

La noción de poder permite trascender la dicotomía micro-macro, así como la dicotomía estructura-actor -esbozada en el apartado siguiente-. Es útil para relativizar los planteamientos que ven lo macro como una "referencia no sólo a las grandes estructuras sociales, sino también a las culturas de las colectividades" y a lo micro como "referencia al tipo de actor consciente y creativo [...] [o] a un 'actuante' menos consciente" (Ritzer, 2002, p. 479). En otros términos, permite articular lo global y lo local, lo social y lo subjetivo.

La sociedad no es una estructura objetiva y externa como tal, es un modelo de estructura inacabado y fallido -aunque en constante revisión de sí misma- que busca consolidarse, objetivarse cotidianamente a partir de las acciones reiterativas y reguladas de los agentes sociales; asimismo, la cultura no es un todo integrado o un conjunto de rasgos, creencias y valores bien delimitados que dotan de identidad a una colectividad, sino que implica un proceso de disputa en torno a la significación donde participan los mismos sujetos sociales y sus grupos.

En este sentido, tanto el proyecto de sociedad global como los procesos culturales particulares tienen historicidad y se imbrican de múltiples maneras pero, regularmente, dicha historicidad, según los cánones de la racionalidad científica, se orienta más a la dilucidación del gran proyecto de sociedad occidental frente a los procesos culturales vividos en espacios más acotados, considerados 
ahistóricos $\mathrm{y}$ atemporales. $\mathrm{O}$, si bien no completamente atemporales, sí temporalmente rezagados, atrasados con respecto a un proyecto civilizatorio propio pensado como único y con la necesidad imperante de civilizar a los otros. En suma, el establecimiento de lo propio como modelo no sólo para pensar al otro, sino también como modelo a ser seguido por ese otro radicalmente negado.

En el caso de la muerte y su análisis desde una perspectiva socio-histórica y cultural, se ha tendido, siguiendo dicho patrón, a analizar el proyecto de sociedad occidental -con la expropiación administrativa que hace del vivir y del morir- y su impacto en la transformación "universal" de las formas de concebir y vivir la muerte. Así, la historiografía de la muerte surgida de la escuela de los Annales (Ariés, 1983; Vovelle, 1974), y sus extrapolaciones al caso mexicano (Pescador, 1992; Zárate Toscano, 2000), historizan las formas de concebir y experimentar la muerte desde una perspectiva esencialmente occidental. Delinean la construcción de una sensibilidad ante la muerte articulada en una mentalidad inconsciente de larga duración, propia de una colectividad homogénea y unificada.

Por su parte, la sociología de la muerte, desde las revisiones teóricas de Bauman (2008) y Elias (2009), hasta las investigaciones empíricas en España (De Miguel, 1995; Jiménez Aboitiz, 2012) y en México (Ferrer, 2003), se orientan hacia los procesos de medicalización, mercantilización, burocratización, secularización y mediatización de la muerte. Se centran fundamentalmente en los dispositivos institucionalizados y su impacto en "mentalidades" alejadas de lo religioso y el sentido de lo sagrado. Observan cómo el proyecto de sociedad y su administración de la muerte impacta en la formación de modos específicos, más o menos homogéneos, de concebirla y experimentarla. 
Aquí cobra importancia el papel de la antropología de la muerte que, tras reconocer que "la muerte es en plural" (Thomas, 1983, p. 17 y ss.), permite generar comparaciones, como la realizada por Ziegler (1976), entre sociedades occidentales y no occidentales, modernas y tradicionales, civilizadas y primitivas ${ }^{3}$. Aunque este tipo de acercamiento percibe, la mayoría de veces, la cultura como un conjunto de creencias, valores, rituales más o menos estáticos, permite observar las diferencias entre distintas maneras de percibir y experimentar la muerte.

Esa es la contribución de trabajos como el de DaMatta (1997), para quien mientras que las sociedades occidentales se centran en la muerte como concepto abstracto, las sociedades relacionales -como prefiere nombrarlas- están enfocadas en los muertos, sus muertos y en la relación establecida con ellos. De igual manera, el trabajo de Barbosa (2010) quien, a partir de la distinción realizada por el antropólogo Guillermo Bonfil Batalla entre un México imaginario -ligado a lo occidental-y un México profundo -ligado a su pasado-presente indígena-, analiza las formas de concebir y de actuar en torno a la muerte en diversos grupos indígenas para mostrar las diferencias sustanciales con respecto a las formas occidentales de vivir la muerte.

Más allá de estos contrastes disciplinarios, Lomnitz (2006) propone un estudio político de las actitudes ante la muerte en México para evidenciar, a través de una perspectiva genealógica, cómo la muerte se convirtió en un tótem nacional.

\footnotetext{
${ }_{3}^{3}$ Aquí resulta interesante la reflexión teórica de Baudrillard (1980) sobre la muerte. A partir de la noción de lo simbólico, el autor realiza una revisión crítica tanto de los argumentos antropomarxistas como antropsicoanalistas con el fin de mostrar en qué medida éstos no logran comprender el sentido del intercambio simbólico en las sociedades primitivas donde la muerte y la vida forman una unidad indisoluble, de tal forma que vivos y muertos son radicalmente diferentes, sino que poseen otro estatuto al poseer cada persona dos estados posibles.
} 


\section{ARTÍCULOS}

No se acerca tanto a las transformaciones en la forma de concebir y experimentar la muerte en sintonía con la incorporación del proyecto societal, ni tampoco a los significados ancestrales indígenas a partir de los que se piensa la muerte, sino al complejo proceso de significación donde la muerte, el hecho real y la construcción simbólica, cobra un papel fundamental en la conformación de un Estado-nación y una cultura popular a partir de una imbricación de imaginarios y prácticas con orígenes diversos.

La muerte se convierte, en el caso mexicano, en el emblema de su identidad a partir del trabajo intelectual durante el periodo postrevolucionario, pero tiene toda una historicidad que permitió este uso de la muerte como símbolo identitario -hoy performativizado para su venta como producto y recurso turístico-.

Este brevísimo recorrido por las formas de estudiar la muerte permite observar la necesidad de acercarnos de otra manera a los entornos latinoamericanos -incluido México-. Esto en razón de que, por su experiencia prehispánica, colonial y poscolonial, estas sociedades muestran distinciones y desigualdades tanto en su interior como respecto a las producciones y procesos occidentales.

Tanto México como, en nuestro caso, Chiapas están ampliamente vinculados a lo occidental pero, al mismo tiempo, se distinguen por sus propios procesos culturales. En estos espacios confluyen el proyecto de sociedad altamente institucionalizado -aunque aún más fallido e inacabado- que busca regular y administrar las formas de vivir y de morir, con procesos culturales concretos en donde se disputan esas formas, se mantienen o emergen otras maneras interesantes de vivir y de morir. 


\section{ARTÍCULOS}

En esas disputas, que implican tanto posibilidades de negociación y de rechazo, juegan un papel fundamental los imaginarios y las prácticas de los sujetos y agentes individuales y grupales, pues es en y a través de ellos que es posible acercarse al proceso cultural por medio del cual se construye, en este caso, la muerte.

\section{Entre la estructura y el sujeto: imaginarios y prácticas en torno a la muerte. Cultura regional como categoría analítica}

En diálogo con De Certeau (1997), el centro de interés de la investigación sociocultural no se encuentra en el sujeto o en el agente por sí mismo, sino en sus operaciones y relaciones cotidianas que exceden la escisión entre lo consciente e inconsciente, lo racional e irracional. De este modo, los imaginarios y las prácticas son, precisamente, las maneras de percibir y hacer cotidianas, las operaciones propias de sujetos que no son independientes y cerradas en sí mismas. Dichas operaciones son posibles a partir de un marco medianamente establecido en el cual pueden pensar y actuar. En este sentido, no existe una separación entre la estructura y el actor, entre lo objetivo y lo subjetivo.

Los imaginarios son, a grandes rasgos, las matrices de la representación o la sustancia de la significación, pero no por ello son un producto acabado y pasivo. En palabras de Gómez, “se organiza[n] como una compleja red de relaciones sobre la que se sostienen los discursos y las prácticas sociales. [Los] imaginario[s] social[es] se manifiesta[n] en lo simbólico (el lenguaje) y en el accionar concreto entre los sujetos en la praxis social" (2001, p. 200-201). 
Son constantemente negociados entre los diversos grupos ubicados en un tiempo y un espacio concreto. Negociación vinculada con elementos de poder, por lo que es posible encontrar, en un mismo contexto socio-histórico, imaginarios dominantes, residuales y emergentes con grados distintos de interrelación ${ }^{4}$.

Por su parte, las prácticas, íntimamente relacionadas con los imaginarios, son las "maneras de hacer" cotidianas, mismas que se encuentran situadas entre la posibilidad ilimitada de elección y creatividad, y el condicionamiento provocado por las restricciones y limitaciones instauradas por una realidad supuestamente bien estructurada (De Certeau, 1997, p. XLIV).

Se refieren al uso que no es un mero consumo pasivo, sino una apropiación y adaptación específica a partir de -y a pesar de- los dispositivos institucionalizados de poder, de acuerdo con sus posibilidades y recursos propios. Es así como la presunta homogeneidad deviene heterogeneidad en lo cotidiano. La primera es un proyecto por alcanzar, la segunda es lo efectivamente dado.

Como conceptos aplicados a la comprensión del proceso de configuración socio-cultural de la muerte se refieren a las formas de concebir, experimentar y actuar en torno a la muerte, en el ir y venir de los dispositivos institucionalizados de poder y las apropiaciones cotidianas de los sujetos que implican mecanismos de producción de sentido.

\footnotetext{
4 Para Williams, exponente de los Estudios Culturales británicos, "lo dominante" es "lo hegemónico". "Lo residual", aquello que "ha sido formado [...] en el pasado, pero todavía se halla en actividad dentro del proceso cultural". Se contrapone a "lo arcaico", aquello que es parte del pasado y útil para su observación, examen y hasta revitalización consciente. "Lo emergente", por su parte, remite a "nuevos significados y valores, nuevas prácticas, nuevas relaciones y tipos de relaciones que se crean continuamente" (2000, p. 144-145).
} 
En otras palabras, la muerte adopta un fuerte sentido institucional pero, a la vez, mantiene algo que la excede y se vincula con la capacidad de los sujetos para apropiarse de esos dispositivos, mezclándolos con otros sentidos. En este ir y venir es donde entran en disputa los imaginarios y prácticas diferenciados que participan en procesos culturales específicos.

Estos procesos culturales son siempre locales y regionales en la medida que se refieren a las formas en cómo se regionalizan y localizan ciertos procesos y proyectos de tendencia global a partir del diálogo con "lo propio". He ahí la razón por la que pensamos lo regional como un proceso intersticial que conecta de modos múltiples las dimensiones local y global, y no como una entidad dada, reconocible y, por tanto, analizable a partir de la presunta existencia de rasgos objetivos o subjetivos.

Las regiones como entidades cerradas y delimitadas sólo existen, nos parece, en tanto que existen relaciones de poder con tendencias a demarcar límites territoriales o identitarios entre lo propio y lo ajeno ${ }^{5}$; mientras que lo regional, como proceso, existe cotidianamente toda vez que se generan interacciones diversas entre proyectos globales y apropiaciones locales o, mejor aún, localizables en contextos espaciales e históricos concretos.

\footnotetext{
${ }^{5}$ A esto se refiere Robertos Jiménez cuando asevera que "las regiones se consideran en una parte de la ciencia social como entes que hay que estudiar para ofrecer una explicación teórica de su 'ser'" (2010, p. 5). Siendo así, las regiones existen en el mundo, forman una parte integrante de la realidad al expresar cierto tipo de relaciones sociales, económicas o históricas. De este modo, el análisis regional no sería más que describir el funcionamiento de la región aludida en tanto que existe por sí misma, así como sus relaciones internas un tanto en detrimento de sus relaciones externas. Se enfoca así su supuesto "ser", más que el proceso a partir del cual llega a ser lo que es en un momento específico de su historicidad.
} 


\section{ARTÍCULOS}

Las regiones pensadas como entidades son producto de una pretensión más o menos intencionada de diferenciación respecto a otras regiones. Sin embargo, en el trazado de una región, sea producto del poder estatal que las delimita a partir de criterios político-administrativos -trazando fronteras territoriales para el control poblacional- o socio-económicos -estableciendo formas de institucionalidad o modos de producción económica a partir de recursos y/o mano de obra existentes-; o por medio del trabajo de demarcación científica que busca rasgos de unidad cultural y sentimientos de pertenencia -partiendo de que esa región ya existe en el imaginario de quienes la conforman-, persiste un criterio de poder que incluye y excluye.

Estos poderes "creadores" de regiones, sea que las formen de manera aparentemente arbitraria o remitiéndose a relaciones consideradas objetivas, tienden a obviar las diferencias que se encuentran al interior de las regiones demarcadas, a pesar de hablar de ellas como una dialéctica entre unidad y diversidad (Giménez, 2010). Al crear una identidad regional crea también diferencias, por lo que resulta más viable hablar de procesos culturales regionales o de una "cultura regional" (Lomnitz, 1995) para aproximarse a la heterogeneidad imperante entre los grupos sociales, aun cuando compartan un espacio y un tiempo concreto.

En resumidas cuentas, hablar de cultura regional es hablar del proceso cotidiano de disputa en torno a la significación, ubicado en un contexto cruzado por conexiones entre niveles diferenciados de interacción y relaciones de interdependencia cada vez más complejas. 
Hablar de cultura regional, donde se cruzan características y demarcaciones político-administrativas, socio-económicas e histórico-identitarias que dan sentido a dicha cultura, es una manera de no hablar de una región como punto de partida por ejemplo, regiones-plan- o punto de llegada -por ejemplo, regiones socioculturales-, sino de emplearla como una categoría analítica que permita acercarse a las dinámicas y los modos que adoptan los procesos de significación y configuración en espacios acotados, con características distintas y formas de organización particulares.

La "cultura regional" como categoría analítica es, desde nuestra perspectiva, una de las formas de aproximarse, desde una perspectiva intermedia, a las relaciones entre lo global y lo local, entre lo micro y lo macro, entre la estructura y la acción, entre el orden social y la agencia. Es al reducir las escalas, pero sin caer en homogeneizaciones o en la búsqueda de unidades aparentes, que se pueden visualizar los distintos y particulares procesos culturales que nos remiten a la apropiación cotidiana de los proyectos globales de corte universalizante.

Tanto la vida cotidiana como los acercamientos analíticos, están influidos por factores que trascienden la inmediatez y los conectan con escalas mayores y niveles de interacción más extensos. Aunque, como propuso el enfoque microhistórico, es a través de la adopción de una escala menor donde se observan las "estrategias familiares e individuales, confrontadas con realidades económicas, con relaciones jerárquicas, en un juego de intercambios entre el centro y la periferia, en una palabra, interacciones que tienen como lugar una aldea" (Ricoeur, 2003, p. 284).

No obstante, decir que tienen como lugar una aldea no es encerrar en ella el sentido último de las interacciones y de las interdependencias, sino mostrar que 
éstas tienen un lugar de emplazamiento que remite a conexiones e interacciones pasadas y presentes, inmediatas y distantes. Hay que franquear, entonces, la trampa del colonialismo que ha llevado a pensar al mundo como un todo "formado por 'pueblos', cada uno con un estilo de vida coherente, o 'cultura'" (Wright, 2004, p. 129), con formas de conexión accidentales, contaminantes o interesadas.

He ahí las razones de hablar de una cultura regional con la que se trata de aprehender, en vez de los significados armónicamente compartidos, las disputas locales cotidianas llevadas a cabo entre los sujetos y sus grupos en espacios que son definidos y redefinidos por criterios de poder macro-estructurales y microrelacionales. En ella se observa cómo se concretizan y materializan las disputas en lugares con mediaciones múltiples; pues, en diálogo con Lomnitz, "una cultura regional es aquella cultura internamente diferenciada y segmentada que se produce a través de las interacciones humanas en una economía política regional" (1995, p. 39).

En estas culturas regionales concretas es donde los agentes sociales despliegan sus imaginarios y prácticas en torno a la lucha por la significación tanto en aspectos de la realidad más específicos -como el caso de la muerte-, o en la noción de la realidad misma. Es desde esta óptica que se puede enfocar un espacio como Tuxtla Gutiérrez, capital del Estado de Chiapas, en el sureste de México: un espacio transpuesto donde confluyen lo rural con lo urbano, donde existe una tensión entre la homogeneidad y la heterogeneidad, y donde convergen imaginarios y prácticas dominantes, residuales y emergentes con orígenes 
diversos, y cuyas luchas remiten a ciertas relaciones político-administrativas, socioeconómicas e histórico-identitarias que es preciso considerar.

Tuxtla Gutiérrez, la ciudad con sendos esfuerzos modernizadores y un intento de reivindicar una identidad zoque que forma parte de su formación, es también un espacio transpuesto porque implica un conjunto de espacios habitados y significados por sujetos que entran en contacto frecuente y cuyas experiencias se llevan a cabo en diferentes espacios - urbanos o rurales, institucionales, íntimos y de tránsito anónimo-, mismos que se relacionan, se mezclan y se condicionan recíprocamente (Escalona, 2014). Es en esos espacios donde se gesta el proceso cotidiano de lucha por la significación en torno a cosas que suceden en el mundo como es, en este caso, la muerte.

Sin embargo, existe un juego entre las delimitaciones realizadas por diferentes poderes entrelazados -como el estatal, el económico y el científico- y las relaciones efectivas de quienes moran dentro de dichas delimitaciones. La cultura regional de Tuxtla Gutiérrez es producto de ese juego. En ella es posible notar no sólo el cruce entre tendencias globalizantes y perspectivas locales, sino la confluencia de características, dinámicas y demarcaciones administrativoterritoriales, socio-económicas e histórico-identitarias que influyen en la forma singular de su proceso cultural.

\section{Los relatos de muerte como aporte metodológico: la muerte como idea, proceso y relación}

Hasta este punto hablamos, primordialmente, de la configuración socio-cultural de la muerte como la manera de nombrar las formas en cómo se concibe, se 
experimenta y se actúa en torno a ella. Pero la noción de configuración es comprendida, en esta propuesta de investigación, en dos sentidos.

Primero como la manera de acercarse a las relaciones entre estructuras, subjetividades e interacciones, de tal modo que la configuración es entendida como una totalidad no sistémica, abierta a reconfiguraciones constantes a partir de las prácticas concretas (De la Garza, 2012). Es una totalidad aparente que no determina, aunque sí ejerce presión sobre quienes participan en ella y, por ende, sobre los significados que construyen. La configuración no es estática ni clausurada, puesto que incluye los dispositivos de poder y las apropiaciones propias y constantes de los sujetos.

Cada esfuerzo de ordenamiento aparece como una configuración provisional que carece de "fijeza" absoluta y "necesidad natural" (Benveniste en Michon, 2010, p. 281), pues es resultado de arreglos y negociaciones sujetos a la transformación. Cualquier tipo de orden, como el "orden social" o el "orden cultural", se refiere a "configuraciones espaciales o temporales que adoptan los procesos" (BlanckCereijido y Cereijido, 2002, p. 33); esto es, a momentos de procesos y no a cosas terminadas.

Pero, por otro lado, la configuración es entendida, en diálogo con Ricoeur (1995), como la configuración narrativa realizada por los sujetos que implica la capacidad de poner en orden y dotar de sentido una serie de acontecimientos discontinuos y heterogéneos. En otras palabras, la configuración realizada a través de la narración -encarnada en el relato-integra la diversidad en la permanencia; es una síntesis de lo heterogéneo, puesto que condensa una diversidad de acontecimientos, de componentes inconexos de la acción, causalidades, entre otras, 
con un principio de orden que es el efecto de la necesidad narrativa y de la totalidad temporal. Esta visión de la configuración implica retomar nuevamente al sujeto y sus operaciones como parte primordial de la reflexión.

Desde esta perspectiva consideramos la configuración socio-cultural, en este caso de la muerte, como una configuración de configuraciones. Es a partir de las configuraciones realizadas por los agentes sociales en sus relatos que es posible acceder a las formas en que se concibe, se experimenta y se actúa en torno a la muerte y su configuración socio-cultural. No obstante, la configuración que es resultado de estos tres elementos actúa sobre los sujetos y sus significados para generar ciertos tipos de configuraciones que revelan, más que meras homogeneidades, las heterogeneidades propias de espacios donde confluyen imaginarios y prácticas diversas.

En suma, la configuración socio-cultural implica las configuraciones narrativas, tanto porque sólo mediante ellas es posible aproximarse a la primera, como porque ésta informa el contenido de las segundas.

La configuración de los relatos tiene, en otros términos, tanto una orientación hacia el sentido -pues buscan otorgar sentido a un acontecimiento indecible e inaprehensible que es reconstruido, en este caso, post-mortem-, como son orientados por relaciones de poder -materiales o materializadas y simbólicas- que vehiculan la producción de ciertos relatos y no de otros -esto implica la orientación de la experiencia y la vivencia misma que es narrada-, además de que les dota de características específicas.

Todo relato es una configuración narrativa propia de los sujetos situados, pero también son producciones configuradas que responden al contexto socio- 
cultural y a las disputas en torno al proceso de significación que se llevan a cabo en él. Siendo así, en los relatos también se entremezclan los dispositivos de poder con los mecanismos de producción de sentido.

Es por esto que para llegar a la configuración socio-cultural de la muerte es necesario pasar, metodológicamente, por las configuraciones realizadas por los sujetos en sus "relatos de muerte", esto es, la narración hecha por los vivos acerca de la muerte de otros, dada la dificultad para captar la muerte, sea la propia o de los otros. Es en este sentido que la dimensión narrativa cobra un papel fundamental para esta propuesta, en la medida que la experiencia de la muerte es siempre una experiencia mediada $\mathrm{y}$, por tanto, reflexiva. Sólo tenemos acercamiento a ella a través de los otros.

Siendo así, estos relatos no colocan en el centro la narración de la propia vida, sino cómo su vida fue tocada por la ruptura, la mayoría de veces considerada abrupta, de una relación espacio-temporal y, por ello, corporal y afectiva con el otro. "La muerte es, como dice Lomnitz, el desmembramiento de un individuo, una disolución que hace sitio al grupo o la especie en conjunto mediante la destrucción de uno de sus miembros" (2006, p. 15). Pero en todo grupo no todos los miembros son iguales, la cercanía o lejanía con ellos genera diferencias imprescindibles en las formas de pensar, vivir y sentir la muerte.

Los relatos de muerte son, a su vez, relatos de acontecimientos que impactaron la propia vida y testimonios que hablan de algo en lo que se participó como testigo. Ponen en el centro, aparentemente, al otro, al que se fue, al ausente, pero no hablan simplemente de la ausencia, sino de cómo se vivió el proceso en que esa ausencia devino tal, las problemáticas vividas en torno a esa ausencia, y las 
formas en que se trata de llenar o ignorar dicha ausencia. Al referirse al otro, se refieren a uno mismo y a las vicisitudes de vivir la muerte del otro, de sobrevivir a quien se fue.

La muerte del otro detona la propia reflexividad al percibirse como ser finito y vulnerable, cuyo destino puede ser imaginado sólo a partir de la experiencia de otras muertes; pero, de igual manera, hace reconocer al sujeto como parte de un entramado de relaciones sociales y de poder donde esas muertes cobran sentido. Es sólo al vivir la muerte cuando se vive el peso de lo que la muerte es dentro un contexto socio-histórico específico.

Cabe señalar que, como todo relato, los relatos de muerte constituyen un entramado de realidad y ficción, hecho que implica pensarlos no sólo en el orden de la racionalidad, sino también de la afectividad. En los relatos de muerte es la mirada del otro afectado la que trata de aprehender la muerte, ya que "el acontecimiento no está ahí ni para el asistente ni para el agonizante cuando 'pasa'" (Ricoeur, 2008, p. 52), pero es ahí donde pueden surgir reflexiones interesantes sobre lo que se piensa y se hace antes, durante y después de la muerte del otro y, en ocasiones, la imaginación de la propia muerte.

Dichos relatos de muerte tienen entre sus principales características de conformación: a) la necesaria contextualización de los sujetos sociales en cuanto a sus orígenes y rasgos generales; $b$ ) el proceso propio de morir y las circunstancias en que el morir se llevó a cabo; c) el momento puntual de la certificación del deceso y las distintas situaciones asociadas a él; d) las acciones de velación, funeral y exequias, o cualquier tipo de prácticas funerarias; e) la vida cotidiana después de la muerte del otro y las recomposiciones que ésta implica en el grupo del que 


\section{ARTÍCULOS}

formaba parte -por ejemplo, el luto y el duelo-; y, por último, f) las diferentes formas de concebir la muerte en un entramado entre lo propio y lo ajeno. En cada una de esas partes surge un entrecruzamiento complejo de acontecimientos, objetos, instancias y procesos macro-sociales y micro-sociales.

Es en estos relatos donde nos parece posible analizar la muerte como idea, como proceso y como relación. Primero, la idea de la muerte se refiere al modo de concebirla, esto es, los modos de pensarla, de nombrarla y hasta de representarla. Implica también las formas de evocarla o de ocultarla, así como las consecuencias en la vida individual y social.

Segundo, la muerte como proceso remite a las maneras de vivirla y experimentarla, mismas en que se puede rastrear el entrecruzamiento de formas institucionales, junto con otros modos regularmente excluidos de vivirla; así como al proceso ritual, muchas veces influido por factores religiosos, a partir del cual se acompaña a quien muere.

Por último, la muerte como relación se dirige hacia aquellas prácticas que buscan generar un lazo con la muerte y los muertos a partir de rituales vinculatorios que permiten promover una idea de relación continuada entre vivos y muertos. Esto incluye desde prácticas que pretenden recordar a quién se fue, hasta medios para establecer relaciones con entidades con otras características de aparición.

A pesar de esta separación analítica, la muerte como proceso y la muerte como relación se encuentran ampliamente articuladas con la muerte como idea; puesto que esa idea, comunicada en discursos y realizaciones prácticas, influye en 
la medida en que es visualizada como proceso o como mero hecho puntual, como relación o como fin de toda relación posible.

Esta forma de observar la muerte implica reconocer la existencia de otras formas de pensar y de vivir la realidad que son igual de importantes que las producciones científicas y académicas pero que han sido sistemáticamente ignoradas o menospreciadas. Son formas que, aunque a veces negocian con las occidentales, otras veces las rechazan o hasta las contradicen, no están exentas de una relación de intercambio y funcionan en la vida cotidiana de los sujetos.

Finalmente, cabe indicar que a pesar del carácter primordial de los relatos, éstos pueden y deben ser apoyados por otras estrategias metodológicas como la observación de campo en los "espacios de muerte" tales como casas, funerarias, panteones; y el análisis de documentos oficiales como cuadros estadísticos, programas de desarrollo, reglamentos y leyes; además de artículos periodísticos que, como señala Gupta, son "textos culturales y documentos sociohistóricos", elaborados por "corresponsales locales" que presentan, en cierta forma, un "conocimiento situado" a pesar de transitar por una serie de "filtros institucionales" que delimitan lo que se puede y no se puede decir $(2015$, p. 103).

\section{Consideraciones finales}

Toda la reflexión desarrollada hasta aquí constituye un intento por esbozar otra manera de visualizar y emplear conceptos que han sido revisados y reformulados para acercarse a fenómenos socio-culturales específicos. La revisión de esos conceptos pretende abrir la posibilidad de una comprensión más completa de procesos que son, en sí mismos, complejos. Tal es el caso de la muerte. Fenómeno 
que sea, quizás, el más complejo en la medida que implica, si bien no un anonadamiento, sí la transformación más radical a la que nuestra existencia humana parece verse sometida.

Esta discusión conceptual permite pensar la muerte como un "objeto" de estudio, pero no en sí y por sí mismo, sino centrándose en el proceso de configuración socio-cultural en un espacio concreto que la hace ser lo que es un momento socio-histórico dado. Esto implica esbozar una suerte de análisis interpretativo del proceso cultural regional, en este caso, en torno a la idea de la muerte, donde se cruzan los dispositivos de poder y los mecanismos de producción de sentido.

De este modo, la propuesta de investigación conlleva un planteamiento hermenéutico en tanto que se dirige hacia la comprensión y la interpretación pero no de los significados por sí mismos en busca de una estructura subyacente que genera homogeneidad, sino del proceso alrededor del cual se forman, articulan, sedimentan y legitiman ciertos significados - con la exclusión correspondiente de otros significados-, atendiendo necesariamente a las instancias que participan en él, así como a la compleja red de interrelaciones que se gestan entre ellas.

Por otro lado, la propuesta presenta un carácter socio-cultural porque reconoce que la cultura es un proceso de disputa en diálogo constante con el proyecto de sociedad que, surgido de la racionalidad moderna occidental, se ha generalizado en el mundo como el único posible. Dicha disputa revela relaciones de poder incluidas en ciertas delimitaciones de espacios con fronteras aparentemente bien definidas y demarcadas, sea por criterios políticoadministrativos, socio-económicos o histórico-identitarios, pero que remiten en 
realidad a una complejidad interna que hace de esos espacios sitios de heterogeneidad, conflicto y apropiaciones diferenciales. Todo espacio, como Tuxtla Gutiérrez, lugar de emplazamiento de la investigación, es un espacio transpuesto aunque con sus propias características- en la medida que implica un ir y venir de personas, objetos, instancias, proyectos, discursos, prácticas. La interacción es constante.

De este modo, aproximarse al proceso de configuración socio-cultural de la muerte es una de las formas de observar las diferencias y disputas, así como las reformulaciones constantes de los imaginarios y las prácticas cotidianas. Reformulaciones que implican un intercambio entre lo dominante, lo residual y lo emergente, hecho que incita al acercamiento hacia otros saberes que, aunque no responden totalmente ni niegan tajantemente los criterios de la racionalidad y de la cientificidad, forman parte de la vida diaria. En este sentido, es preciso reconocer la validez de estos saberes como modos de configuración de lo real.

Dicha configuración es aprehensible a través -pero no únicamente- de los "relatos de muerte". Relatos en los que el protagonista es el que se fue, el ausente, pero cuya ausencia impulsa un sentido de reflexividad en quien narra, quien le sobrevive y cuenta una historia en donde se entretejen imaginarios y prácticas con orígenes diversos -en este caso, prehispánicos, coloniales-católicos, postcolonialesmodernos-, además de elementos racionales y afectivos, reales y ficcionales. Es en la configuración de esta trama narrativa donde aparecen los trazos de cómo se concibe, cómo se experimenta y cómo se actúan en torno a la muerte; en otras palabras, la muerte como idea, como proceso de morir y como relación con nuestros muertos. 


\section{ARTÍCULOS}

La muerte, nuestra muerte, continúa siendo una preocupación cotidiana. No sólo por el temor a la muerte en sí, sino por todas sus implicaciones personales, sociales, económicas, políticas y religiosas actuales. Pero aún permanece la duda de si la muerte es el fin de todo. Al menos podemos decir que un recurso para no perecer completamente es reconocer el carácter social de la vida y de la muerte, es decir, que se permanece en los "labios de los vivos", de quienes nos sobreviven, de quienes cuentan lo acontecido desde sus dinámicas vitales aún inconclusas. Además de que es sólo desde el otro que se queda narrando su vivencia con respecto al otro que se fue, que parece posible aproximarse a la concepción, la experiencia y la relación diferencial, e incluso desigual, establecida con la muerte y los muertos.

Con todo lo anterior es posible tener un acercamiento menos reduccionista y reificante hacia ese fenómeno tan complejo que denominamos muerte, pues se reivindica el papel de los sujetos, sus grupos y el proceso de significación cotidiano. De igual manera, se reconoce que la homogeneidad no existe en la práctica, pues las disputas cotidianas muestran las complementariedades, negociaciones y contradicciones propias de la existencia humana.

\section{Referencias}

Aguilera Portales, R. E. y J. González Cruz (2009). La muerte como límite antropológico. El problema del sentido de la existencia humana. Gazeta de Antropología, (25/2), versión electrónica.

Ariês, P. (1983). El hombre ante la muerte. Madrid: Taurus. 
| Cuatrimestral Facultad de Humanidades Campus VI Reserva de Derechos al Uso Exclusivo No.: 04-2018-060814012200-203| ISSN: 2594-1755 Año II | Número 4 | Septiembre-Diciembre 2018

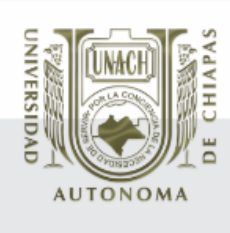

\section{ARTÍCULOS}

Asad, T. (1993). Genealogies of Religion. Discipline and reasons of power in Christianity and Islam. Baltimore and London: The Johns Hopkins University Press.

Barbosa Sánchez, A. (2010). La muerte en el imaginario del México profundo. México: Juan Pablos Editor, Universidad Autónoma del Estado de Morelos.

Baudrillard, J. (1980). El intercambio simbólico y la muerte. Caracas: Monte Ávila Editores.

Bauman, Z. (2008). Miedo líquido: la sociedad contemporánea y sus temores. Buenos Aires: Paidós.

Castro-Gómez, S. (2007). Decolonizar la universidad. La hybris del punto cero y el diálogo de saberes. En Santiago Castro-Gómez y Ramón Grosfoguel (comps.). El giro decolonial: reflexiones para una diversidad epistémica más allá del capitalismo global (pp. 79-91). Bogotá: Siglo del Hombre Editores; Universidad Central, Instituto de Estudios Sociales Contemporáneos y Pontificia Universidad Javeriana, Instituto Pensar.

De Certeau, M. (1997). La invención de lo cotidiano I. Artes de hacer. México: Universidad Iberoamericana, Instituto Tecnológico y de Estudios Superiores de Occidente.

De la Garza Toledo, E. (2012). La metodología marxista y el configuracionismo latinoamericano. En Enrique de la Garza Toledo y Gustavo Leyva (eds.). Tratado de metodología de las ciencias sociales: perspectivas actuales (pp. 229-255). México, D.F.: Fondo de Cultura Económica, Universidad Autónoma Metropolitana-Iztapalapa.

De Marinis, P. (2005). 16 comentarios sobre la(s) sociología(s) y la(s) comunidad(es), en Papeles del CEIC, (15), 1-39. 


\section{ARTÍCULOS}

De Miguel, J. M. (1995). “El último deseo". Para una sociología de la muerte en España. REIS. Revista Española de Investigaciones Sociológicas, (71-72), 109-156.

Elias, N. (2009). La soledad de los moribundos. México: Fondo de Cultura Económica.

Escalona Victoria, J. L. (2011). Estado: la manufactura disputada del orden negociado y de los autó-matas inacabados. Estudios Sociológicos, XXIX (86), 389-413.

Escalona Victoria, J. L. (2014). Espacios transpuestos: haciendo etnografía entre el campo y la ciudad. Entrediversidades. Revista de Ciencias Sociales y Humanidades, (2), 175-205.

Ferrer, E. (2003). El lenguaje de la inmortalidad. Pompas fúnebres. México: Fondo de Cultura Económica.

Giménez, G. (2000). Territorio, cultura e identidades. La región socio-cultural. En R. Rosales Ortega (Coord.). Globalización y regiones en México (pp. 19-51). México: Programa Universitario de Estudios sobre la Ciudad, Facultad de ciencias Políticas y Sociales, Universidad Autónoma de México, Miguel Ángel Porrúa.

Gómez, P. A. (2001). Imaginarios sociales y análisis semiótico. Una aproximación a la construcción narrativa de la realidad. Cuadernos de la Facultad de Humanidades y Ciencias Sociales - Universidad Nacional de Jujuy, (17), 195-209.

González González, N. (2000). El estudio de la muerte como fenómeno social. La reflexión metodológica y el trabajo epidemiológico. Estudios Sociológicos, XVIII (3), 677-694. 
| Cuatrimestral Facultad de Humanidades Campus VI Reserva de Derechos al Uso Exclusivo No.: 04-2018-060814012200-203| ISSN: 2594-1755 Año II | Número 4 | Septiembre-Diciembre 2018

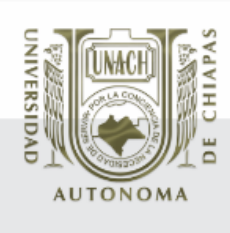

\section{ARTÍCULOS}

Jacorzynski, W. (2008). En la cueva de la locura: aportación de Ludwig Wittgenstein a la antropología social. México: Centro de Investigaciones y Estudios Superiores en Antropología Social.

Jankélévitch, V. (2004). Pensar la muerte. Buenos Aires: Fondo de Cultura Económica.

Jiménez Aboitiz, R. (2012). De la muerte (de)negada a la muerte reivindicada? Análisis de la muerte en la sociedad española actual: muerte sufrida, muerte vivida y discursos sobre la muerte (tesis doctoral inédita). Departamento de Sociología y Trabajo Social, Facultad de Ciencias Económicas y Empresariales, Universidad de Valladolid, Valladolid, España.

Levinas, E. (1994). Dios, la muerte y el tiempo. Madrid: Cátedra.

Lomnitz, C. (1995). Las salidas del laberinto. Cultura e ideología en el espacio nacional mexicano. México: Joaquín Mortiz, Planeta.

Lomnitz, C. (2006). Idea de la muerte en México. México: Fondo de Cultura Económica.

Mendoza Luján, J. E. (2012). “Espántame, panteón”. Los espacios y usos del cuerpo muerto. Vita Brevis. Revista electrónica de estudios de la muerte, (1), 9-27.

Moebius, S. (2012). Posestructuralismo y ciencias sociales. En Enrique de la Garza Toledo y G. Leyva (eds.). Tratado de metodología de las ciencias sociales: perspectivas actuales (pp. 525-566). México: Fondo de Cultura Económica, Universidad Autónoma Metropolitana-Iztapalapa.

Ovalle Pastén, D. (2013). Narración, tiempo humano y muerte: reflexión teórica por una hermenéutica de la muerte. Revista Historia Autónoma, (2), 161-175. 
| Cuatrimestral Facultad de Humanidades Campus VI Reserva de Derechos al Uso Exclusivo No.: 04-2018-060814012200-203| ISSN: 2594-1755

Año II | Número 4 | Septiembre-Diciembre 2018

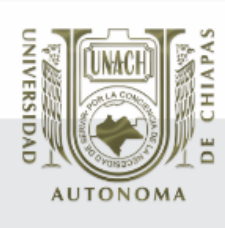

ARTÍCULOS

Wright, S. (2004). La politización de la cultura. En Mauricio Boivin y Ana Rosato (comps.). Constructores de otredad. Una introducción a la Antropología Social y Cultural (pp. 128-141). Buenos Aires: Antropofagia.

Zárate Toscano, V. (2000). Los nobles ante la muerte en México. Actitudes, ceremonias y memoria (1750-1850). México, D.F.: El Colegio de México, Instituto de Investigaciones Dr. José María Luis Mora.

Ziegler, J. (1976). Los vivos y la muerte. México: Siglo XXI. 